\title{
The professional and ethical dilemmas of the two-child limit for Child Tax Credit and Universal Credit
}

\begin{abstract}
Child Tax Credit and Universal Credit provide means-tested support for low-income families. The government have introduced a two-child limit for these benefits meaning that the child element of Child Tax Credit and Universal Credit will no longer be awarded for third or subsequent children born after 06 April 2017. The government argue that the benefit system should provide a fair deal for the tax payer and that families claiming benefits should face the same financial choices as those in work. However, it has been argued that there is an inherent moral injustice in linking benefit entitlement to the size of the family and that there will be an increase in child poverty.
\end{abstract}

Firstly this paper will discuss the ethics of limiting state financial support on the basis of family size with reference to how far social justice can be achieved in a 'needs based' benefits system. Secondly, there will be an analysis of the most controversial element of this policy - the so called 'rape clause' where an exception is applied if a claimant can demonstrate that their third or subsequent child is born as a result of non-consensual sexual intercourse. Finally the paper will identify potential implications for anti-oppressive practice.

\section{The ethics of moving away from a 'needs-based' benefits system}

The two-child limit has been described as 'pernicious' in that it creates a system where some children are seen as more deserving recipients of welfare provision than others (Child Poverty Action Group, 2016). Linking the levels of social security benefits to family size raises fundamental questions about the welfare 'safety net'. The two-child policy introduces an eligibility criteria where financial support is not linked to the needs of individual children and instead is based on a judgment about the extent to which the state is prepared to support low income families.

The move away from a system based on individual need is underpinned by another dominant ideology: the benefit system will reward those who are perceived to be doing the 'right thing' and penalise those who behave in the opposite manner. Clearly in relation to the two-child policy the perceived correct behaviour is to limit the number of children born into a family. CPAG (2016) argue that this is a flawed philosophy as it is impossible for any of us to predict our future circumstances. For example, unemployment, separation, bereavement or failed contraception could lead to a change in family composition and a possible need to claim means-tested benefits. These scenarios severely undermine the simplistic, binary notion of us making 'appropriate' or 'inappropriate' choices. Similarly, Hills (2017) has emphasised that discourse around welfare benefits is undermined by the 'myth' that benefit claimants are a static, homogenised group when the reality is that across time our circumstances change and at certain points in life we are all recipients of welfare support.

A benefit system based on family size is not without precedent. In 2016 seventeen US states administered some form of 'welfare family cap' (University of California, 2016). In twelve of these states eligibility for cash grants is denied to children born into a family already in receipt of government benefits. Interestingly the maximum family grant (MFG) in California was abolished in June 2016 on the basis that it pushes the most vulnerable families into higher levels of poverty and had not altered the reproductive behaviour of claimants. In the UK there is little evidence that other areas of the government's welfare reform programme have produced the behavioural changes sought. For example, significant numbers of tenants affected by the 'bedroom tax' have not moved to alternative properties and relatively small numbers of claimants subject to the benefit cap have moved into work (DWP, 2015, IFS 2014). 
An analysis of the ethics of the two-child limit should acknowledge the government's rationale for introducing this benefit change. Since 2010 successive governments have pursued a welfare reform agenda based on the belief that the welfare system is too complex and lacks incentives to encourage people on benefits to move into work. The government maintain that the reshaped system is based on fairness and affordability. Since 2010 both David Cameron and his successor as Prime Minister Theresa May have been keen to emphasise that a fair benefits system is based on the principles of social justice. Crossley $(2017$, p31) states that the focus of the 'compassionate conservatism' version of social justice is on the individual and families, with 'poverty presented as an effect of personal failings as opposed to an inadequate income and its effects'. This interpretation of social justice does not adequately recognise the way that poverty and inequality are perpetuated by systems and structures (Rawls 1999) or the impact that oppression and discrimination has on marginalised individuals (Lister, 2007). It is arguably also at odds with the Social Mobility Commission view that positive social change requires a fundamental reworking of the education system, housing market, local economies and the labour market (Social Mobility Commission 2016).

The interpretation of social justice that underpins the introduction of the two-child limit very much centres on the 'choices' which families make about their lives: 'Benefit entitlement adjusts automatically to family size, whilst families supporting themselves solely through work do not see their incomes rise in the same way when they have more children.' (HM Government 2016,p5). Dorling (2010) has argued that in countries such as the UK where there are high levels of income inequality statements such as the above and policies such as the 2-child limit are more prevalent as the population as a whole is less compassionate. This fits with the notion of 'othering' (Patrick 2016) in which people experiencing poverty related problems can themselves establish a hierarchy of who is more or less deserving of state support.

\section{Exceptions to the two-child limit policy and the ethics of the 'rape clause'}

In January 2017 the government published details of the exceptions to the 2-child limit policy (DWP 2017a). Claimants will be exempt from this policy in the following three circumstances:

- Children likely to have been born as a result of rape

- Children living long-term with family and friends

- Children born in a multiple birth

For the first two exceptions listed above a third-party evidence system has been introduced. This requires professionals such as social workers, GPs, midwives and health visitors to verify that a claimants' circumstances meet one of the exceptions. Children may be living with family or friends on an informal basis and for the exception to apply in these circumstances a professional will be required to confirm that the child being cared for would otherwise have been cared for by a local authority. Similarly evidence will need to be provided to the benefit authorities if a more formal arrangement is in place (e.g. adoption of guardianship order). There are certainly capacity issues for professionals who will have these new responsibilities placed on them. We may also see some changes in the dynamics of the service user-professional relationship which could create ethical concerns where, for example, a social worker effectively becomes a 'gate-keeper' for a client to access benefits for their children.

Without question the most significant ethical issues (both philosophical and practical) of the entire two-child limit policy relate to the 'rape-clause'. The principles behind the 'rape clause' have been strongly criticised by a wide range of organisations (for example, Engender, Child Poverty Action Group, Citizens Advice Scotland). Engender (2017, p.3) state that 'This clause will re-traumatise 
individual women who have survived rape by forcing them to disclose sexual violence at a time and context not of their own choosing, on pain of deeper impoverishment.' The benefit system is underpinned by a 'burden of proof' philosophy that rests with the claimant and these concerns about the nature and timing of disclosure are real and compelling. If a third or subsequent child is born as a result of non-consensual conception at a time when the claimant was in an abusive relationship and subject to 'control or coercion' an exception which also apply. However, the claimant will need to confirm that she is no longer living with the alleged perpetrator. The government argue that this is necessary to ensure that perpetrators do not benefit financially from the exception. However, it has been argued that this fails to recognise the difficulty that victims can have in leaving an abusive partner (Machin, 2017).

Department for Work and Pensions guidance (DWP 2017b) states that in addition to social workers and health professionals, evidence will be accepted through the completion of an approved form by a specialist worker from Rape Crisis, Refuge, Women's Aid Federation or the Survivors Trust.

Following the consultation period it was confirmed that police officers are not included as third party assessors. The government state that the third-party evidence model will mean that neither Department for Work and Pensions or Her Majesty's Revenue and Customs staff will need to directly question claimants or take evidence from them. Decision makers are instructed to accept evidence from the approved third-party on the basis that the claimant had demonstrated that there circumstances are consistent with 'those of a person whose child has been conceived as a result of non-consensual sex'.

As part of an analysis of this issue it is important to examine both the official form that third parties need to complete and the DWP guidance that has been issued to accompany the form. This reveals not only important technical detail in relation to the responsibilities placed on third parties, but also says much about the ethics and philosophy that underpin this exception. The guidance states that professionals should only complete the exception form in the 'course of your professional duties'. This seemingly simple statement is open to a wide range of interpretations about what constitutes 'professional duties'. This will be an issue that organisations and professionals will need to clarify and to be mindful of their relationship with service users. The guidance states that there is no requirement to seek evidence to confirm a claimant's circumstances and that the third party is only confirming an understanding that what has been reported to them (the form asks only that the third party ticks a box to support the exception). Clearly the ambiguity of this statement is intended to prevent the need for a claimant to report and provide evidence in a way that would be required, for example, in a criminal setting. However, this gives a level of discretion and responsibility to a third party that they might not feel comfortable with and which again provides a potential area of conflict with a service user.

There are multiple tensions within the third-party model: the specialist professionals with the greatest level of understanding of the needs of women who have been raped will perhaps be the least inclined to disclose information to the DWP/HMRC. Other professionals who are categorised as approved third parties may not have the knowledge and skills to appropriately understand the complex needs of this client group. There is a risk that professionals will make judgements about how a rape victim presents and behaves and consciously or unconsciously profile their service users accordingly. Some campaigning groups (CPAG, Citizens Advice Scotland) have argued that the list of third-party professionals should be extended to include advice workers and even family and friends or religious leaders. The rationale for this is that if the DWP and HMRC are prepared to accept reasonable evidence it should be allowed to come from the people who are the closest and most trusted by the claimant. 
The rape exception has also raised concerns in relation to privacy and confidentiality. In a letter to the Employment Minister Damian Hinds the Social Security Advisory Committee (SSAC 2017) stated that given the limited number of situations in which this exception applies it would be straightforward to identify which of these applied to a particular claimant. The Minister considered that privacy could not be guaranteed but asserted that the DWP are experienced in dealing with sensitive data (Hinds 2017). CPAG (2016) have identified an extensive range of situations in which an 'accidental disclosure' could be made. These include where there are joint claims for tax credits or universal credit with a current or future partner or where there are older children who are assisting with household finances. Typically a tax credits or universal credit recipient will be claiming a range of other benefits and may need to seek advice about debt issues, student finance or discretionary grants. In each of these situations it may become apparent that the rape exception is being applied (Machin, 2017).

The government maintains that women will not be forced to prove that they have been raped in order to secure welfare payments (HM Government 2017, p9). 'The Government does recognise that the handling of this exception is very sensitive. As we introduce the measure we will set up procedures that are mindful of the sensitivities involved. Neither DWP nor HMRC staff will question the claimant about the incident other than to take the claim and receive the supporting evidence from the third party professional.'

\section{Implications for anti-oppressive practice}

There is an overt political dimension to any discussion of anti-oppressive practice in relation to the two-child limit for means tested benefits. Thompson (2006) described the challenges associated with emancipatory practice when a 'New Right' philosophy focusing on the retrenchment of welfare provision dominates. The acceleration of this philosophy since 2010 has resulted in many professionals working within the health and social care sector being forced to contemplate how they can appropriately support service users in a climate of cuts and austerity which run counter to their own professional values. The underlying challenge, therefore, for practitioners is to keep antioppressive values at the core of practice when working within a system that many would view as promoting inequality and structural oppression. Banks and Gallagher (2009) consider individual and social justice to be linked and again this poses challenges for anti-oppressive practice when outcomes for individuals are interwoven with a programme of welfare reform characterised by judgment and conditionality. These tensions created by the welfare state in a capitalist society are of course nothing new (see for example the writing of Marshall 1972 and O'Connor 1973) but we are witnessing an unprecedented period of change.

The language and terminology used to both describe benefit claimants and to justify welfare reform has been the subject of considerable academic debate. Garthwaite (2011) has drawn parallels between the contemporary use of phrases such as 'shirkers' and 'strivers' and historical depictions of the deserving and undeserving poor. Roulstone (2015) describes the way in which government policy is legitimised by the portrayal of vulnerable groups in the mass media. This means that we see government policy driven by popular media narrative rather than by a critical examination of social and economic need. It is clear that language plays a key role in anti-oppressive practice. Dalrymple and Burke (2006, p150) have emphasised the importance of language in the connections and relationships that we build. Furthermore, they highlight the impact of language on professional relationships 'the language that we use to describe the people with whom we are working characterizes the nature of the relationship and, in turn, how we will intervene in their lives'. Professionals supporting service users who are affected by benefit changes such as the two-child limit will need to be mindful that many claimants internalise the negative terms which are often 
used to describe them, but can also use prejudicial language to describe others who are perceived to be in similar positions to themselves. The very fact that the exception described in the previous part of this paper is already referred to as the 'rape clause' demonstrates how value-laden language quickly becomes part of the professional lexicon.

Ethical role modelling can play an important part in anti-oppressive practice. Leaders at all levels of an organisation (service directors, team leaders, senior case workers) are responsible for setting the ethical standards which they expect of staff and which then translate into the way in which services are delivered to clients (Millar and Poole 2011). Banks and Gallagher (2009) describe some of the key features of positive role modelling as avoiding favouritism and ensuring that the most marginalised and vulnerable are given a voice and fair access to services. This has implications for the way in which professionals work with those who are affected by the benefit changes introduced through welfare reform. An ethical approach must be underpinned by a recognition of the systematic oppression and inequality often experienced by benefit claimants and a genuine desire to improve their situation. The two-child limit for means tested benefits has been identified as having a disproportionately negative impact on women from some ethnic backgrounds, refugee women, women who have larger families for religious reasons and families with disabled children. Positive role modelling will be of particular importance when working with these client groups.

Dominelli (2010) emphasises that an understanding of inequality and oppression is central to antioppressive practice. Whilst oppression operates on many levels practitioners need to demonstrate an ideological awareness to effectively support those affected by changes to benefit system such as the two-child limit. An overtly campaigning or critical stance may sit uncomfortably with some professionals, or indeed be incompatible with their role. However, an understanding of the impact of political decisions on the lives of service users is important. This paper has discussed some of the sensitive issues around confidentiality and privacy that the two-child policy raises and concerns have been raised about protecting claimant's anonymity should they wish to challenge a decision to a social security appeal tribunal. Practitioners employed by public sector bodies will also be mindful to comply with the public sector equality duty which requires organisations to advance equality of opportunity and foster good relations between those who share a protected characteristic under the Equality Act 2010 (including pregnancy and maternity) and those who do not.

\section{Conclusion}

The full impact of the two-child policy will not be felt until the end of the current parliament. By $2020 / 21$ it is estimated that 640,000 families will be affected with families losing up to $£ 2,780$ per year for each additional child in the family. Many claimants affected by the two-child policy will also be affected by reductions to other benefits. Practitioners in the health and social care sector will need to provide support to help claimants cope with the cumulative impact of these measures. The two-child policy raises fundamental questions about the role of the welfare state, the move away from a needs based system and the extent to which political decisions can and should influence public behaviour.

For practitioners the two-child policy raises a number of ethical dilemmas, not least the challenge of providing support to service users who are subject to a policy which may conflict with established professional values. Significant concerns and questions persist about the third party evidence model and the new, perhaps unwanted, responsibilities this places on professionals to confirm circumstances of the most sensitive and private nature to benefit authorities. These dilemmas will 
almost certainly follow the principle established by Handy in that they can be managed but not solved. (Handy 1994).

\section{References}

Banks, Sarah and Gallagher Anne (2009). Ethics in professional life. Basingstoke: Palgrave Macmillan

Child Poverty Action Group (2016). Exceptions to the limiting of the individual Child Element of Child Tax Credit and the Child Element of Universal Credit to a maximum of two children CPAG's response. Accessed on June 20 2017:

http://www.cpag.org.uk/sites/default/files/Two\%20child\%20limit\%20consultation CPAG\%20respon se.pdf

Child Poverty Action Group (2017). Two-child limit for Universal Credit: 200,00 more children put in poverty. Accessed July 01 2017: http://www.cpag.org.uk/content/two-child-limit-universal-credit200000-more-children-put-poverty

Crossley, Stephen (2017). The 'official' social justice: an examination of the Coalition government's concept of social justice. Journal of Poverty and Social Justice. vol 25 no 1, 21-33, DOI:

10.1332/175982717X14842282011532

Dalrymple, Jane and Burke, Beverley (2006). Anti-Oppressive Practice. Social care and the law. Maidenhead: Open University Press

Department for Work and Pensions (2015). Evaluation of removal of the spare room subsidy. Accessed on June 292017.

https://www.gov.uk/government/uploads/system/uploads/attachment data/file/506407/rsrsevaluation.pdf

Department for Work and Pensions (2017a). Child Tax Credit: exceptions to the 2 child limit. Accessed on 29 June 2017: https://www.gov.uk/guidance/child-tax-credit-exceptions-to-the-2-child$\underline{\text { limit }}$

Department for Work and Pensions (2017b). Approved third party professionals who can complete these forms. Accessed on July 10 2017: https://www.gov.uk/government/publications/support-fora-child-conceived-without-your-consent/approved-third-party-professionals-who-can-completethese-forms

Dominelli, Lena (2010). Social Work in a Globalizing World. Cambridge: Polity

Dorling, Daniel (2012). Fair Play. A Daniel Dorling reader on social justice. Bristol: Policy Press

Engender (2017). Engender submission of evidence on the two-child limit for Tax Credits \& Universal Credit to the Scottish Parliament Social Security Committee. Accessed on 03 July 2017:

https://www.engender.org.uk/content/publications/Engender-submission-of-evidence-on-the-twochild-limit-on-Tax-Credits-and-Universal-Credit-to-the-Scottish-Parliament-Social-Security-

Committee.pdf

Garthwaite, Kayleigh (2011). 'The language of shirkers and scroungers?' Talking about illness, disability and coalition welfare reform. Disability \& Society, 26:3, 369-372, DOI:

10.1080/09687599.2011.560420 
HM Government (2016). Exceptions to the limiting of the individual Child Element of Child Tax Credit and the Child Element of Universal Credit to a maximum of two children. Public consultation. Acessed on May 20:

2017: https://www.gov.uk/government/uploads/system/uploads/attachment_data/file/561641/exc eptions-to-the-limiting-of-the-individual-child-element-of-child-tax-credit-and-the-child-element-ofuniversal-credit-to-a-maximum-of-2-children.pdf

Handy, Charles (1994). The Age of Paradox. Massachusetts: Harvard Business School Press.

HM Government (2017). Consultation response - Exceptions to the limiting of the individual Child Element of Child Tax Credit and the Child Element of Universal Credit to a maximum of two children. Acccessed on May 20 2017: http://dera.ioe.ac.uk/28059/2/government-response-to-universalcredit-and-child-tax-credit-exceptions-to-the-2-child-limit-consultation.pdf

Hinds, Damian (2017). The Social Security (Restrictions on Amounts for Children and Qualifying Young persons) Amendment Regulations 2017. Accessed on July 10 2017:

https://www.gov.uk/government/uploads/system/uploads/attachment data/file/602215/damianhinds-response-to-ssac-2-child-exceptions.pdf

Hills, John (2017). Good times, bad times. The welfare myth of them and us. Bristol: Policy Press

Institute for Fiscal Studies (2014). Coping with the cap? Accessed July 02 2017:

https://www.ifs.org.uk/publications/7482

Kennedy, Steven, Bate, Alex and Keen, Richard (2017). The two child limit in tax credits and Universal Credit. House of Commons Library Briefing Paper. Accessed on July 10 2017:

http://researchbriefings.parliament.uk/ResearchBriefing/Summary/CBP-7935

Lister, Ruth (2007). Social justice: meanings and politics, Benefits, 15, 2, 113-25

Machin, Richard (2017). The two child limit for Universal Credit and Child Tax Credit. Adviser volume 180. Accessed July 10 2017: https://medium.com/adviser/the-two-child-limit-for-universal-creditand-child-tax-credit-c5e0eb342738

Marshall, Thomas (1972). Value problems of welfare capitalism. Journal of Social Policy, vol 1, pp 1530

Millar, Carla and Poole Eva (2011). Ethical Leadership: Global challenges and perspectives.

Basingstoke: Palgrave Macmillan

O'Connor, James (1973). The Fiscal Crisis of the State. New York: St Martin's Press

Patrick, Ruth (2016). Living with and responding to the 'scrounger' narrative in the UK: exploring everyday strategies of acceptance, resistance and reflection. Journal of Poverty and Social Justice, volume 24, number 3, October 2016, pp 245-259, DOI:10.1332/175982716X14721954314887

Rawls, John (1999) A theory of justice. Oxford: Oxford University Press

Roulstone, Alan (2015). Personal Independence Payments, welfare reform and the shrinking disability category. Disability and Society. 30:5, 673-688, DOI:

10.1080/09687599.2015.1021759

Social Mobility Commission (2016). State of the Nation 2016. Social Mobility in Great Britain.

Accessed 01 June 2017: 
https://www.gov.uk/government/uploads/system/uploads/attachment data/file/569410/Social M obility Commission 2016 REPORT WEB 1 .pdf

Social Security Advisory Committee (2017). The Social Security (Restrictions on Amounts for Children and Qualifying Young Persons) Amendment Regulations 2017. Accessed on July 02 2017:

https://www.gov.uk/government/uploads/system/uploads/attachment data/file/590932/ssac-todamian-hinds-2-child-exceptions.pdf

Thompson, Neil (2006). Anti-discriminatory practice. Basingstoke: Palgrave Macmillan

University of California. Center on reproductive rights and justice (2016). Bringing Families out of 'Cap'tivity: the Path Toward Abolishing Welfare Family Caps. Accessed June 26 2017:

https://www.law.berkeley.edu/wp-content/uploads/2015/04/2016-Caps FA2.pdf 